\title{
ABSENCE OF WOLBACHIA IN RED PALM WEEVIL, RYNCHOPHORUS FERRUGINEUS OLIVIER (COLEOPTERA: CURCULIONIDAE): A PCR-BASED APPROACH
}

\author{
Ali, H. ${ }^{1,2}-$ MuHAMmad, A. ${ }^{1,2}-$ HoU, Y. ${ }^{1,2^{*}}$ \\ ${ }^{1}$ State Key Laboratory of Ecological Pest Control for Fujian and Taiwan Crops, Fujian \\ Agriculture and Forestry University, Fuzhou 350002, China \\ ${ }^{2}$ Fujian Provincial Key Laboratory of Insect Ecology, College of Plant Protection, Fujian \\ Agriculture and Forestry University, Fuzhou 350002, Fujian, China \\ *Corresponding author \\ e-mail: ymhou@fafu.edu.cn; phonelfax: +86-591-8376-8654 \\ (Received $8^{\text {th }}$ Nov 2017; accepted $27^{\text {th }}$ Feb 2018)
}

\begin{abstract}
Among the intracellular bacterial symbionts, the genus Wolbachia (Rickettsiaceae: Rickettsiales) is one of the most abundant taxa associated with reproductive systems of various insects. It is cytoplasmic inherited endosymbiont that induce various reproductive alterations. Characterization analysis has revealed that a number of arthropods harbour Wolbachia sp. estimates from 20-80\%, with emphasize on Coleopterous insects (41 species have been reported so far). Therefore, in the context of broad existence and unique phenotypic actions to alter reproductive systems of various insect, we aimed to determine the intriguing possibility of this endosymbiont from one of the deadliest palm pest, i.e. red palm weevil (RPW), Rynchophorus ferrugineus (Curculionidae) from different geographical locations using polymerase chain reactions (PCR) with four sets of Wolbachia-specific primers (SPs) along with one pair of universal bacterial primer (BP). Parallel analysis was also carried out with Wolbachia strain isolated from whitebacked plant hopper, Sogatella furcifera (Homoptera: Delphacidae), as a positive control. Our analysis confirmed the absence of Wolbachia sp. across the various life stages of RPW reared in laboratory or captured from the field. Moreover, the phylogenetic analysis of all closely related Wolbachia-mediated weevils were compiled and retrieved from NCBI database indicates the extent of transfection of this bacterium into RPW for the future work on biological control of RPW. This study may facilitate to understand further evolutionary consequences of Wolbachia infection in weevils.
\end{abstract}

Keywords: RPW, biological control, endosymbiotic bacteria, Wolbachia, PCR

\section{Introduction}

A number of symbiotic bacteria associated with insects profoundly influence their host physiology. Among these endosymbionts, Wolbachia sp. belongs to order Rickettsiales, is widely distributed in invertebrates (Arthropods). The evidences are mounting that Wolbachia can infect a number of insect species (20-80\%) (Werren and Windsor, 2000; Jiggins et al., 2001; Tagami and Miura, 2004; Hilgenboecker et al., 2008; Zug and Hammerstein, 2012) from different orders including Diptera, Hymenoptera, Coleoptera, Lepidoptera, Orthoptera, and Hemiptera/Homopter (Werren and Windsor, 2000). Extrapolations of this percentage among the total number of insects and nematode species make Wolbachia one of the most abundant endosymbiont. This genus has also been reported from filarial nematodes, the causative agents of river blindness and elephantiasis in human (Fenn et al., 2006). Wolbachia has the potential to distort the host reproductive system by various phenotypic effects (Blagrove et al., 2012; Ali et al., 2016) such as cytoplasmic incompatibility (Poinsot et al., 2003) (CI), parthenogenesis induction (Stouthamer et al., 1999) (PI), male killing (MK) (Jiggins et 
al., 2001) and feminization (Negri et al., 2006). Among these phenotypes, MK, PI, and feminization are highly selective advantageous to female-biased sex ratio while the CI is related to decreasing the number of offspring by reducing the egg hatchability. Phylogenetic analysis has revealed that a total of 8-11 distant Wolbachia supergroups designated as A-K has been proposed so far (Lo et al., 2002; Casiraghi et al., 2005). Among these supergroups, A and B are high presumably distributed in arthropods while supergroup $\mathrm{C}$ and $\mathrm{D}$ belong to terrestrial nematodes with the exception of endosymbionts from Mansonella spp., which are recognized in supergroup F. Anyhow, new supergroups with the range of novel Wolbachia-mediated hosts has not yet been completely investigated, although new phylogenetic lineages along with novel host are progressively discovered (Casiraghi et al., 2005).

Moreover, breeding behavior, (Gazla and Carracedo, 2009; Miller et al., 2010), sex determination, (Rigaud, 1997), eusociality (Stouthamer et al., 1999) and speciation (Bordenstein, 2003) of the host may also be profoundly affected or altered by Wolbachia sp. It is also known to play roles both protective or antagonistic in some RNA viral infections in Drosophila (Osborne et al., 2012) and establishes obligate associations as observed in all infected nematodes (Fenn and Blaxter, 2004; Fenn et al., 2006) and rarely in some arthropods (Dedeine et al., 2005; Hosokawa et al., 2010). Remarkable biology, and diverse phenotypic effects of Wolbachia and its potential application for the control of vector-borne diseases such as dengue fever, malaria or filariasis (Kambris et al., 2009) offers promising tools to control various economically important invasive species of agriculture and medical importance.

The beetle superfamily Curculionoidea (Insecta: Coleoptera) is one of the most plenteous, diverse, dominant and successful animal group containing more than 60,000 described and likely to contain further 220,000 undescribed species (Oberprieler et al., 2007). Among the Curculionoidea family, red palm weevil (RPW), Rhynchophorus ferrugineus (Olivier) is one of most invasive pest of almost 26 palm species (Malumphy and Moran, 2009) including date palm, Phoenix dactylifera L, oil palm, Elaeis guineensis (Murphy and Briscoe, 1999), coconut palm, Cocos Nucifera, and Canary Island date palm, Phoenix canariensis. The RPW is a concealed tissue borer which undergoes complete metamorphosis (life cycle going through egg, larvae, pupae and adult stages as shown in Fig. 1) and the greater part of its life stages are found inside the palm tree.

Damage manifestations are showed by the presence of tunnels in the trunk, oozing of thick yellow to brown fluid from the tree, the presence of chewed up plant tissue in and around openings in the trunk, the occurrence of a fermented smell from the fluid inside infested tunnels in the trunk, and/or breaking of the trunk or toppling of the palm crown (Kaakeh et al., 2001). In China, damages of RPW initially reported in Guangdong during 1997 and spread rapidly to other parts (Chongqing, Fujian, Hainan Island, Hong Kong, Guangdong, Guangxi, Guizhou, Jiangsu, Jiangxi, Shanghai, Sichuan, Taiwan, Tibet, Yunnan and Zhejiang) (Li et al., 2009). Nowadays, this pest is widely distributed, found in Oceania, Asia, Africa, Europe (several countries around the mediterranean basin) and the Middle East (Howard et al., 2001).

Symbiotic association between beetles and microbial consortia have been broadly investigated. From last few decades, more than thirty weevils have been investigated to harbor Wolbachia (Lachowska et al., 2010), with number increasing gradually (41 beetles as shown in Table 1). Many of which belong to supergroup A or B, except the one discovered in Rhinocyllus conicus (Froehlich) that belongs supergroup F (Lo et al., 
2002). In view of the widespread distribution as well as the manipulation of host mating and reproduction, Wolbachia has attracted the interest of biologists because they maybe used as a novel environmentally friendly tool for insect pest control. Bearing in mind the importance of Wolabchia, first, we investigate the presence of Wolbachia infection in RPW with the aim to explore the potential use of this endosymbiont as biological control agent against it. This is the first novel study to interrogate the existence of Wolbachia in RPW using PCR-based approach. Secondly, according to our best knowledge we compiled all weevils which have been proven to Wolbachia positive from previous literatures (Table 1) and finally, we constructed a phylogenetic relationship between previously identified Wolbachia strains in closely related coleopterans species with RPW for further understanding the evolutionary consequences of Wolbachia infection in weevils.

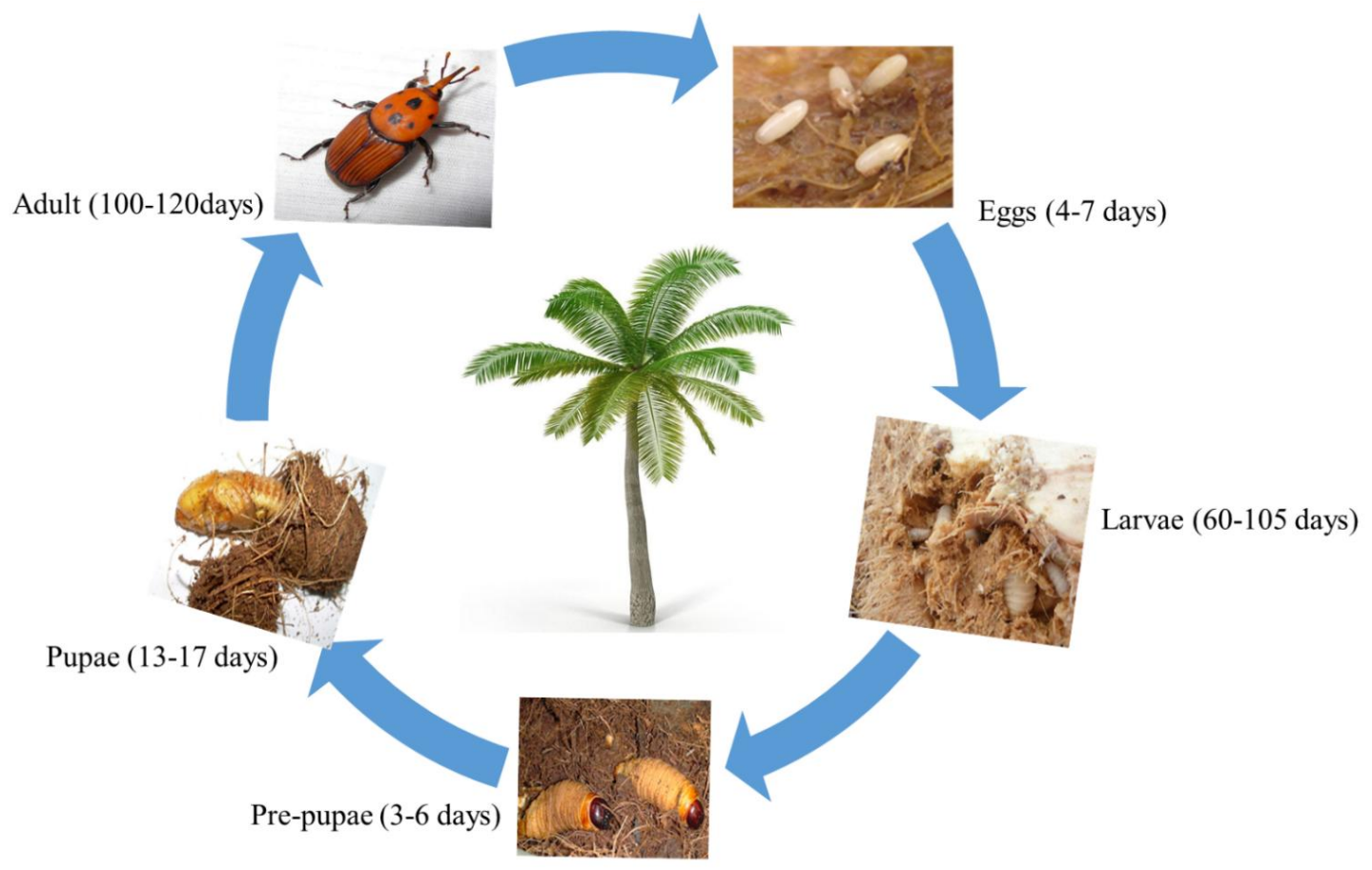

Figure 1. Life cycle (egg to adult stage) of red palm weevil (RPW), Rynchophorus ferrugineus (Curculionidae). Number of days may vary according to envirnmental conditions

\section{Material and methods}

\section{Insect collections and rearing}

The present study was conducted at the Key Laboratory of Insect Ecology, Department of Plant Protection, Fujian Agriculture and Forestry University, FuzhouChina. Specimens of RPW were collected from different geographical locations (Table 2 and Fig. 2) during 2014-2017 from infested palm trees. From every location at least 10 specimens were captured. Collected adults and larvae were placed in perforated plastic boxes with host plant tissues and transported to the laboratory for further rearing and DNA extraction. Laboratory population was maintained under control conditions (Temp 25-28 ${ }^{\circ} \mathrm{C}$, RH 65-70\%, 12:12 light-dark cycle) (Hou and Weng, 2010) and provided with sugarcane (Saccharum officinarum) for feeding and oviposition. 
Table 1. Wolbachia infection on the basis of Wolbachia outer surface protein (wsp) and filamenting temperature sensitive mutant $Z$ protein (FtsZ) in all known Coleopteran species reported so far

\begin{tabular}{|c|c|c|c|c|}
\hline \multicolumn{2}{|c|}{ Coleopteran hosts } & \multicolumn{2}{|c|}{$\begin{array}{c}\text { Accession no. of } \\
\text { Wolbachia }\end{array}$} & \multirow[t]{2}{*}{ References } \\
\hline Scientific name & Family & wsp gene & fts $Z$ gene & \\
\hline Sitophilus zeamais & Curculionidae & AB469362 & - & Kageyama et al., 2010 \\
\hline Otiorhynchus sulcatus & Curculionidae & - & - & Son et al., 2008 \\
\hline Adalia bipunctata & Curculionidae & AJ130714 & - & Hurst et al., 1999 \\
\hline Naupactus cervinus & Curculionidae & GQ402145 & - & Rodriguero et al., 2010 \\
\hline Xylosandrus germanus & Curculionidae & AB359039 & - & Kawasaki et al., 2010 \\
\hline Ceutorhynchus obstrictus & Curculionidae & - & HM012590 & Floate et al., 2011 \\
\hline Hypera postica & Curculionidae & - & - & Iwase et al., 2015 \\
\hline Sitophilus oryzae & Curculionidae & - & KP762388 & Li et al., 2015 \\
\hline Lissorhoptrus oryzophilus & Curculionidae & - & GU478334 & Chen et al., 2012 \\
\hline Rhinocyllus conicus & Curculionidae & - & - & Campbell et al., 1992 \\
\hline Conotrachelus nenuphar & Curculionidae & GU013552 & - & Zhang et al., 2010 \\
\hline Tribolium madens & Tenebrionidae & AF275546 & - & Fialho and Stevens, 2000 \\
\hline Tribolium confusum & Tenebrionidae & AF020083 & - & Ming et al., 2015 \\
\hline Aulacophora nigripennis & Chrysomelidae & GU236978 & - & Jeong et al., 2009 \\
\hline Chelymorpha alternans & Chrysomelidae & DQ842458 & - & Baldo et al., 2006 \\
\hline Altica lythri & Chrysomelidae & KF163375 & - & Jackel et al., 2013 \\
\hline Aphthona nigriscutis & Chrysomelidae & - & AY136550 & Roehrdanz et al., 2006 \\
\hline Hermaeophaga mercurialis & Chrysomelidae & - & KF163372 & Jackel et al., 2013 \\
\hline Callosobruchus latealbus & Chrysomelidae & AB545610 & - & Kondo et al., 2011 \\
\hline Diabrotica virgifera zeae & Chrysomelidae & DQ091305 & - & Giordano et al., 1997 \\
\hline Oreina liturata & Chrysomelidae & HG970634 & - & Montagna et al., 2014 \\
\hline Oreina cacaliae & Chrysomelidae & HG325863 & - & Montagna et al., 2014 \\
\hline Diabrotica virgifera virgifera & Chrysomelidae & - & AY136551 & Roehrdanz and Levine, 2007 \\
\hline Diabrotica cristata & Chrysomelidae & - & AY007556 & Clark et al., 2001 \\
\hline Callosobruchus chinensis & Chrysomelidae & AB038339 & & Kondo et al., 2011 \\
\hline Diabrotica barberi & Chrysomelidae & - & AY136552 & Roehrdanz and Levine, 2007 \\
\hline Brontispa longissima & Chrysomelidae & MG345108 & - & Ali et al., 2018 \\
\hline Octodonta nipae & Chrysomelidae & MG551861 & & Unpublished data \\
\hline Harmonia axyridis & Coccinellidae & - & KM288833 & Goryacheva et al., 2015 \\
\hline Pityogenes chalcographus & Scolytinae & DQ993183 & - & Avtzis et al., 2008 \\
\hline Hypothenemus hampei & Scolytidae & AF389084 & - & Vega et al., 2002 \\
\hline Byturus tomentosus & Byturidae & AJ585376 & - & Malloch et al., 2005 \\
\hline Megabruchidius sophorae & Bruchidae & AB545607 & - & Kondo et al., 2011 \\
\hline Callosobruchus analis & Bruchidae & AB469357 & - & Kageyama et al., 2010 \\
\hline Oryzaephilus mercator & Silvanidae & KJ152808 & - & Li et al., 2015 \\
\hline Oryzaephilus surinamensis & Silvanidae & AB469190 & - & Kageyama et al., 2010 \\
\hline Luciola unmunsana & Lampyridae & FJ156729 & - & Jeong et al., 2009 \\
\hline Lasioderma serricorne & Anobiidae & AB469359 & - & Kageyama et al., 2010 \\
\hline Stegobium paniceum & Anobiidae & AB469917 & - & Kageyama et al., 2010 \\
\hline Byctiscus venustus & Rhynchitidae & GU236986 & - & Jeong et al., 2009 \\
\hline Anthrenus verbasci & Dermestidae & AB469915 & - & Kageyama et al., 2010 \\
\hline
\end{tabular}

Note: Scientific names, families and their accession numbers are given. Blank boxes indicates either not available or not known accession numbers from NCBI database 
Table 2. Tested specimens of red palm weevil (RPW), Rynchophorus ferrugineus (Curculionidae), their collection year and place of collection

\begin{tabular}{c|c|c|c|c|c}
\hline S. No & $\begin{array}{c}\text { Date of } \\
\text { collections }\end{array}$ & Collected samples & $\begin{array}{c}\text { Strain } \\
\text { name }\end{array}$ & Host plant & $\begin{array}{c}\text { Original place of } \\
\text { collections }\end{array}$ \\
\hline 1 & $16 / 10 / 2015$ & Egg (lab collected) & LE & S. officenarum & Fuqing, Fujian, China \\
2 & $16 / 10 / 2015$ & Lab larvae & LL & S. officenarum & Fuqing, Fujian, China \\
3 & $16 / 10 / 2015$ & Lab pupa & LP & S. officenarum & Fuqing, Fujian, China \\
4 & $16 / 10 / 2015$ & Lab adult male & LM & S. officenarum & Fuqing, Fujian, China \\
5 & $16 / 10 / 2015$ & Lab adult female & LF & S. officenarum & Fuqing, Fujian, China \\
6 & $12 / 5 / 2014$ & Hainan adult male & HM & P. canariensis & Hainan province, China \\
7 & $12 / 5 / 2014$ & Hainan adult female & HF & P. canariensis & Hainan province, China \\
8 & $10 / 7 / 2014$ & Guanxi adult male & GM & P. canariensis & Guanxi province, China \\
9 & $10 / 7 / 2014$ & Guanxi adult female & GF & P. canariensis & Guanxi province, China \\
10 & $2 / 3 / 2015$ & Shangai adult male & SM & P. canariensis & Shangai, China \\
11 & $2 / 3 / 2015$ & Shangai adult female & SF & P. canariensis & Shangai, China \\
12 & $2 / 4 / 2015$ & Longyan adult male & LogM & P. canariensis & Longyan, Fujian, China \\
13 & $2 / 4 / 2015$ & Longyan adult female & Logf & P. canariensis & Longyan, Fujian, China \\
14 & $11 / 7 / 2015$ & Xiamen adult male & XM & P. canariensis & Xiamen, Fujian, China \\
15 & $11 / 7 / 2015$ & Xiamen adult female & XF & P. canariensis & Xiamen, Fujian, China \\
16 & $15 / 8 / 2015$ & Fuqing adult male & FM & P. canariensis & Fuqing, Fujian, China \\
17 & $15 / 08 / 2015$ & Fuqing adult female & FF & P. canariensis & Fuqing, Fujian, China \\
18 & $25 / 8 / 2016$ & Zhangzhou adult male & ZM & P. canariensis & Zhangzhou, Fujian, China \\
19 & $25 / 8 / 2016$ & Zhangzhou adult female & ZF & P. canariensis & Zhangzhou, Fujian, China \\
20 & $3 / 9 / 2017$ & Ningde adult male & NM & P. canariensis & Ningde, Fujian, China \\
21 & $3 / 9 / 2017$ & Ningde adult female & NF & P. canariensis & Ningde, Fujian, China \\
\hline
\end{tabular}

\section{DNA extraction}

For DNA extraction all samples (Table 2 and Fig. 2) were sterilized with $75 \%$ alcohol and rinsed three times with autoclaved double distilled water. Total genomic DNA extraction was performed from various life stages (egg, larvae, pupa, male and female) of lab-reared specimens, while only field caught adult stage (male or female) from different geographical locations using DNeasy Blood and Tissue Kit (Qiagen, Valencia, USA) in accordance with the manufacturer's protocol with final elution step repeated twice in $100 \mu \mathrm{l}$ of buffer AE. The concentration and purity of the extracted DNA was quantified using a NanoDrop 2000 spectrophotometer (Thermo Scientific, Wilmington, DE).

\section{PCR amplification for Wolbachia detection}

The presence of Wolbachia in extracted DNA of RPW specimens was screened using PCR amplification with four Wolbachia SPs and a universal bacterial primer ( $\mathrm{Pu}$ et al., 2016) (Table 3). PCR reactions contained a total volume of $25 \mu 1$ comprised of $2 \mu 1$ of template DNA, $12.5 \mu \mathrm{l}$ of 2X Taq PCR Master-mix (Tiangen Biotechnology Beijing, China), $1 \mu 1$ of each primer, and $8.5 \mu 1$ double distilled water. Each reaction run with a positive control (Wolbachia DNA from Sogatella furcifera (Horvath) and negative control (without DNA). Amplified PCR products were run on $1 \%$ agarose gel $(0.5 \mathrm{ug} / \mathrm{ml}$ ethidium bromide, TRIS-EDTA-Buffer; Fisher, Waltham, MA) and visualized using UV illuminator. 


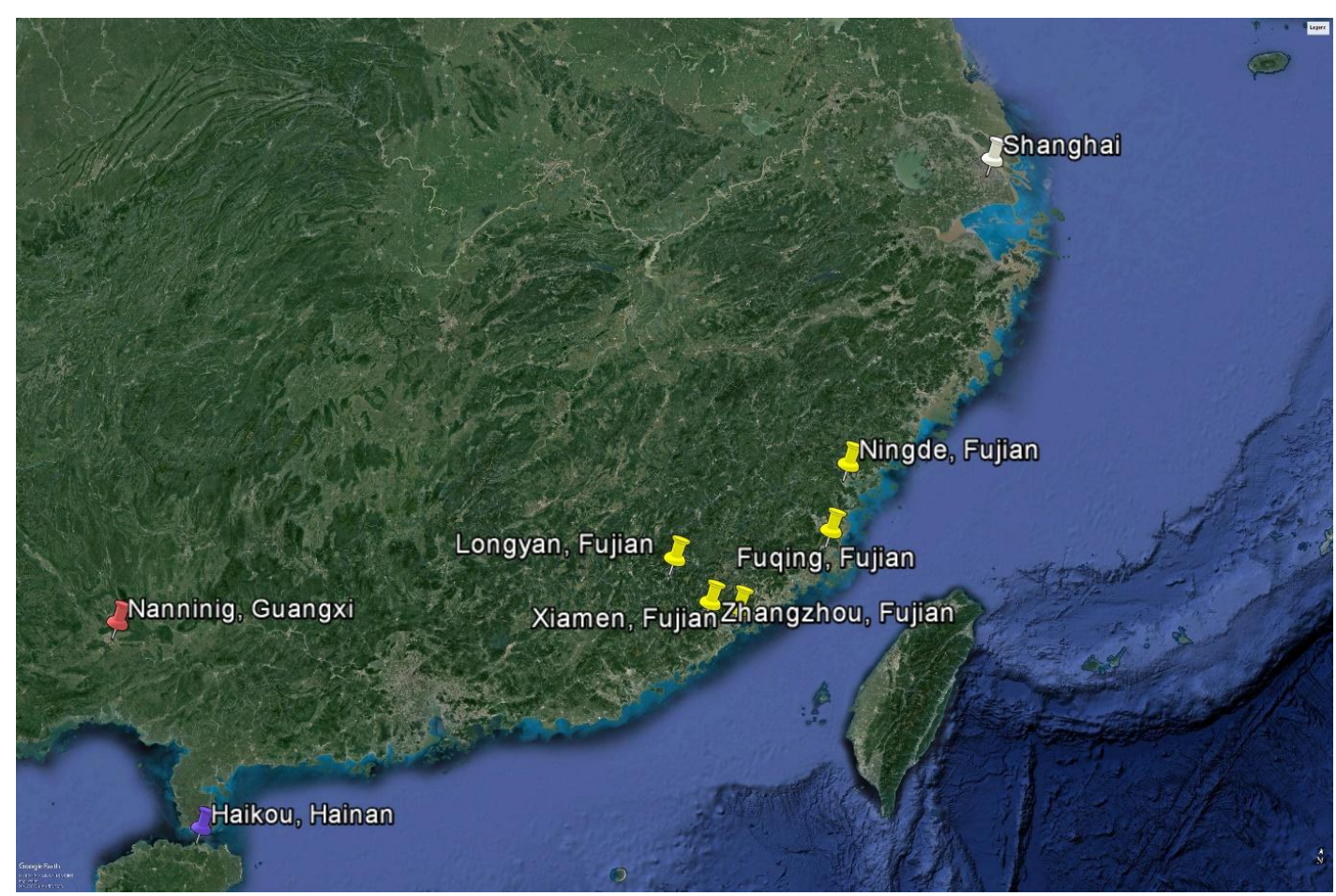

Figure 2. Map of sampling sites from different geographic locations (Fujian, Guangxi, Shanghai and Hainan province) of china. Red palm weevil (RPW), Rynchophorus ferrugineus (Curculionidae) specimens collected from same locations represent same color, while different colors represent variable provinces of china. The map was obtained from google earth (https://www.google.com/earth/desktop/)

Table 3. Four sets of Wolbachia specific primers (SPS) along with universal bacterial primer (BP) with PCR thermal cycling conditions used in this study

\begin{tabular}{|c|c|c|c|c|}
\hline Primer & Primer sequence & $\begin{array}{l}\text { PCR cycling } \\
\text { conditions }\end{array}$ & FL & Reference \\
\hline \multirow[t]{4}{*}{$\begin{array}{l}\text { Wolbachia } \\
\text { SPs }\end{array}$} & $\begin{array}{l}\text { 1) wsp81F: 5'-TGG TCC AAT AAG TGA TGA AGA AAC-3' } \\
\text { wsp691R: 5'-AAA AAT TAA ACG CTA CTC CA-3' }\end{array}$ & $\mid \begin{array}{llll}94 & { }^{\circ} \mathrm{C} \text { for } 4 \mathrm{~min}, 40 \mathrm{~s} \\
\text { at } & 94 \quad{ }^{\circ} \mathrm{C}, \quad 40 \quad \mathrm{~s} & \text { at } \\
55 & { }^{\circ} \mathrm{C}, 1 \text { min at } & 72 \\
{ }^{\circ} \mathrm{C} \text {, Extension step of } \\
10 \text { min at } 72{ }^{\circ} \mathrm{C}\end{array}$ & $\approx 600 \mathrm{bp}$ & Zhou et al., 1998 \\
\hline & $\begin{array}{l}\text { 2) wsp 1: 5'-GGATCCGGGTCCAATAAGTGATGAAGAAAC-3' } \\
\text { wsp2: 5'-GGATCCTTAAAACGCTACTCCAGCTTCTGC-3' }\end{array}$ & -do- & -do- & Baldo et al., 2006 \\
\hline & $\begin{array}{l}\text { 3) wspF: 5'-GGGTCCAATAAGTGATGAAGAAAC-3' } \\
\text { wspR: 5'-TTAAAACGCTACTCCAGCTTCTGC- 3' }\end{array}$ & -do- & -do- & Ming et al., 2015 \\
\hline & $\begin{array}{l}\text { 4) FtsF: 5'-GTA TGC CGA TTG CAG AGC TTG-3' } \\
\text { FtsR: 5'- GCC ATG AGT ATT CAC TTG GCT-3' }\end{array}$ & $\mid \begin{array}{l}95{ }^{\circ} \mathrm{C} \text { for } 10 \mathrm{~min}, \\
1 \mathrm{~min} \text { at } 95{ }^{\circ} \mathrm{C}, 1 \mathrm{~min} \\
\text { at } 55{ }^{\circ} \mathrm{C}, 2 \mathrm{~min} \text { at } \\
70{ }^{\circ} \mathrm{C} \text {, Extension step } \\
\text { of } 5 \text { min at } 72{ }^{\circ} \mathrm{C}\end{array}$ & $\approx 750 \mathrm{bp}$ & Kondo et al., 2011 \\
\hline $\begin{array}{l}\text { Universal } \\
\mathrm{BP}\end{array}$ & $\begin{array}{l}\text { 1) 27F: 5'-TCG ACATCGTTTACGGCGTG-3' } \\
\text { 1492R: 5'-CTA CGGCTACCTTGTTACGA-3' }\end{array}$ & $\mid \begin{array}{l}94{ }^{\circ} \mathrm{C} \text { for } 3 \mathrm{~min}, 40 \mathrm{~s} \\
\text { at } 94 \quad{ }^{\circ} \mathrm{C}, 40 \mathrm{~s} \\
55^{\circ} \mathrm{C}, 1 \mathrm{~min} \text { at } 72{ }^{\circ} \mathrm{C}, \\
\text { Extension } 5 \text { min } \\
72^{\circ} \mathrm{C}\end{array}$ & $\approx 1400 \mathrm{bp}$ & $\mathrm{Pu}$ and Hou, 2016 \\
\hline
\end{tabular}

SPs: specific primers; BP: bacterial primer; FL: fragment length; PCR: polymerase chain reactions 


\section{Wolbachia positive strain}

Wolbachia strain used in this study as a positive control was originally isolated from a lab-reared adult of $S$. furcifera (Horvath) (Homoptera, Delphacidae) known to be infected by Wolbachia under the accession number of FJ713766.1 retrieved from National Center for Biotechnology Information (NCBI) database (https://www.ncbi.nlm.nih.gov/nuccore/224797910). PCRs were carried with total volume of $50 \mu \mathrm{l}$ comprised of $4 \mu 1$ of template DNA, $50 \mu 1$ of $2 \mathrm{X}$ Taq PCR Master mix (Tiangen Biotechnology Beijing, China), $2 \mu 1$ of each primer, and $17 \mu 1$ double distilled water to amplify the targeted genes. The PCR products, after evaluation of positive amplification verified through gel electrophoresis, were subjected to cloning and transformations. A $2 \mu \mathrm{l}$ of purified amplification product from 1\% agarose gel extracted using MiniElute Gel Extraction Kit (Qiagen) was directly ligated into the pGEM T-Easy Cloning Vector (Promega, Madison, WI) in accordance with the protocol. Ligation products were transformed into T1 Competent Cells (Qiagen), which were plated on $0.5 \%$ ampicillin Luria-Bertani broth (LB) selection plates (S-Gal LB Agar Blend, Sigma-Aldrich, St Louis, MO) and incubated overnight at $37^{\circ} \mathrm{C}$. At least three positive clones were picked and labeled according to sample and incubated in $1000 \mu 1 \mathrm{LB}$ broth (0.5\% ampicillin) for $10 \mathrm{~h}$ at $37^{\circ} \mathrm{C}$ and $300 \mathrm{rpm}$. After shaking, $2 \mu \mathrm{l}$ finally confirmed sample via diagnostic PCR were send to sequencing company (life science Company).

\section{Phylogenetic analysis}

We retrieved the sequences of previously identified Wolbachia strains (41 species) from closely related weevils to RPW by running search on NCBI GeneBank database (http://www.ncbinlmnih.gov/BLAST). All Wolbachia strains retrieved from the NCBI GeneBank were aligned using ClustalW and tree was constructed with MEGA5.05 software (Tamura et al., 2011). The aligned sequences were corrected manually if necessary and best fit model was chosen for cladogram analysis.

\section{Results}

\section{Detection of Wolbachia in RPW}

According to our PCR results, all four Wolbachia SPs (wsp81F-wsp691R, wspFwspR, wsp1-wsp2 and ftsF-ftsR) yielded negative results except for the positive control as shown in Table 4. Based on these results, we comprehensively rejected the hypothesis of the presence of this endosymbiont in field-collected, or lab-reared RPW samples (egg, larvae, pupa, and adult) and concluded that RPW is not naturally infected by Wolbachia sp. (Table 4). On the other hand, bacterial universal primer (27F, 1492R) showed visible bands $(\approx 1400 \mathrm{bp})$ on agarose gel across the all tested life stages (Table 4) except for the negative control which shows the purity of DNA isolated from all targeted specimens. Contrary with above assumptions, all four Wolbachia SPs including Wolbachia outer surface protein (wsp) and filamenting temperature sensitive mutant $\mathrm{Z}$ protein $(f t s Z$ ) genes were used against positive control ( $S$. furcifera) yielded $\approx 600 \mathrm{bp}$ and $\approx 750 \mathrm{bp}$ respectively after running on $1 \%$ agarose gel electrophoresis (Table 4). To ensure the authenticity of targeted regions of $w s p$ and $f t s Z$ genes from positive control were blasted against NCBI database and the results demonstrated the same sequence fragments under the accession numbers of FJ713766 and JN560721 respectively. Visible fragments only in positive control indicates the integrity of DNA. 
Table 4. Wolbachia infected (+) or uninfected (-) diagnostic PCR results against laboratory reared and field collected specimens of red palm weevil (RPW), Rynchophorus ferrugineus (Curculionidae) with four pairs of Wolbachia SPs and one pair of universal BP

\begin{tabular}{|c|c|c|c|c|c|c|}
\hline & \multirow[b]{2}{*}{ Sample } & \multirow{2}{*}{$\begin{array}{c}\text { Universal BP } \\
27 \mathrm{~F} \\
1492 \mathrm{R}\end{array}$} & \multicolumn{4}{|c|}{ Wolbachia SPs } \\
\hline & & & $\begin{array}{c}\text { wsp81 F } \\
\text { wsp691R }\end{array}$ & $\begin{array}{l}\text { wspF } \\
\text { wspR }\end{array}$ & $\begin{array}{l}\text { wsp1 } \\
\text { wsp2 }\end{array}$ & $\begin{array}{l}\text { ftsF } \\
\text { ftsR }\end{array}$ \\
\hline \multirow[t]{5}{*}{ Laboratory reared } & LE & + & - & - & - & - \\
\hline & LL & + & - & - & - & - \\
\hline & LP & + & - & - & - & - \\
\hline & LM & + & - & - & - & - \\
\hline & LF & + & - & - & - & - \\
\hline \multirow[t]{17}{*}{ Field collected } & HM & + & - & - & - & - \\
\hline & $\mathrm{HF}$ & + & - & - & - & - \\
\hline & GM & + & - & - & - & - \\
\hline & GF & + & - & - & - & - \\
\hline & SM & + & - & - & - & - \\
\hline & $\mathrm{SF}$ & + & - & - & - & - \\
\hline & $\log M$ & + & - & - & - & - \\
\hline & $\operatorname{Logf}$ & + & - & - & - & - \\
\hline & $\mathrm{XM}$ & + & - & - & - & - \\
\hline & $\mathrm{XF}$ & + & - & - & - & - \\
\hline & $\mathrm{FF}$ & + & - & - & - & - \\
\hline & $\mathrm{ZM}$ & + & - & - & - & - \\
\hline & $\mathrm{ZF}$ & + & - & - & - & - \\
\hline & NM & + & - & - & - & - \\
\hline & $\mathrm{NF}$ & + & - & - & - & - \\
\hline & $\mathrm{NC}$ & - & N/A & N/A & N/A & $\mathrm{N} / \mathrm{A}$ \\
\hline & $\mathrm{PC}$ & N/A & + & + & + & + \\
\hline
\end{tabular}

SPs: specific primers; BP: bacterial primer; N/A: not applied; NC: negative control; PC: positive control

\section{Phylogenetic relationship of previously described Wolbachia strains from order Coleoptera}

Wolbachia is widely distributed in Coleopteran insects and majority of weevil species have been reported Wolbachia infected which are taxonomically closely related to RPW. However, in our PCR assay, we were unable to detect the presence of Wolbachia sp. in RPW. Total length of alignments were $\approx 600 \mathrm{bp}$ for $26 \mathrm{wsp}$ and $\approx 750 \mathrm{bp}$ for $10 \mathrm{ftsZ}$ gene sequences were used to construct phylogenetic tree, while 3 weevils (Otiorhynchus sulcatus. Hypera postica, Rhinocyllus conicus) (Table 1), we were unable to find their Wolbachia sequence from NCBI database. We construct a phylogenetic relationship between previously identified Wolbachia strains in closely related coleopterans species with RPW in order to understand the future of Wolbachia transfection into RPW and exploit it in pest management. Wolbachia strains were named after the host insect species, and the GeneBank accession number are listed as well (Fig. 3). 


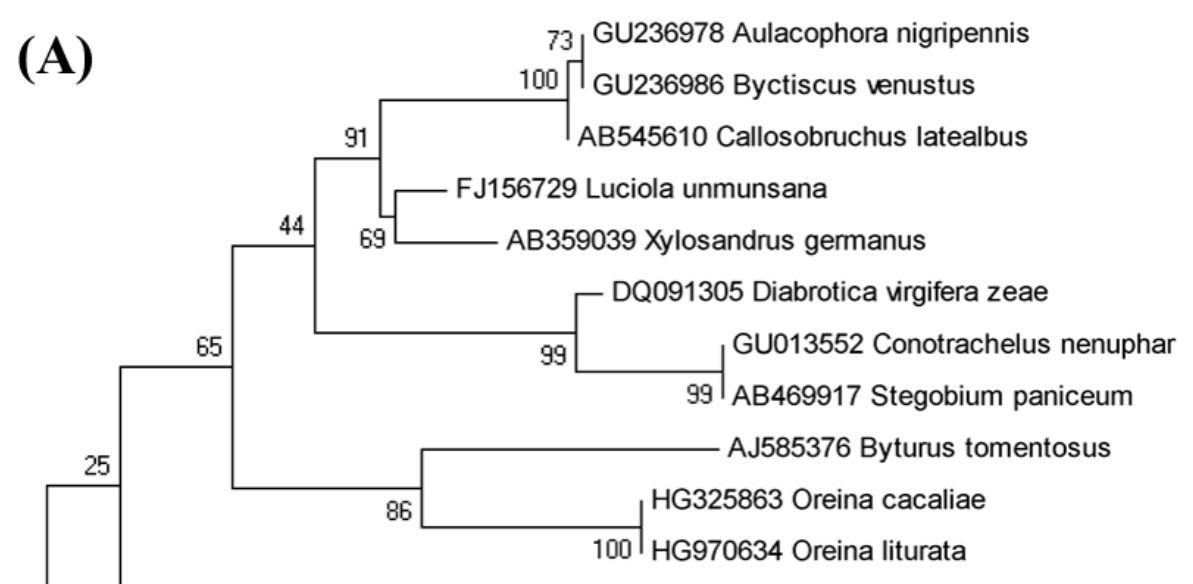

AB469357 Callosobruchus analis

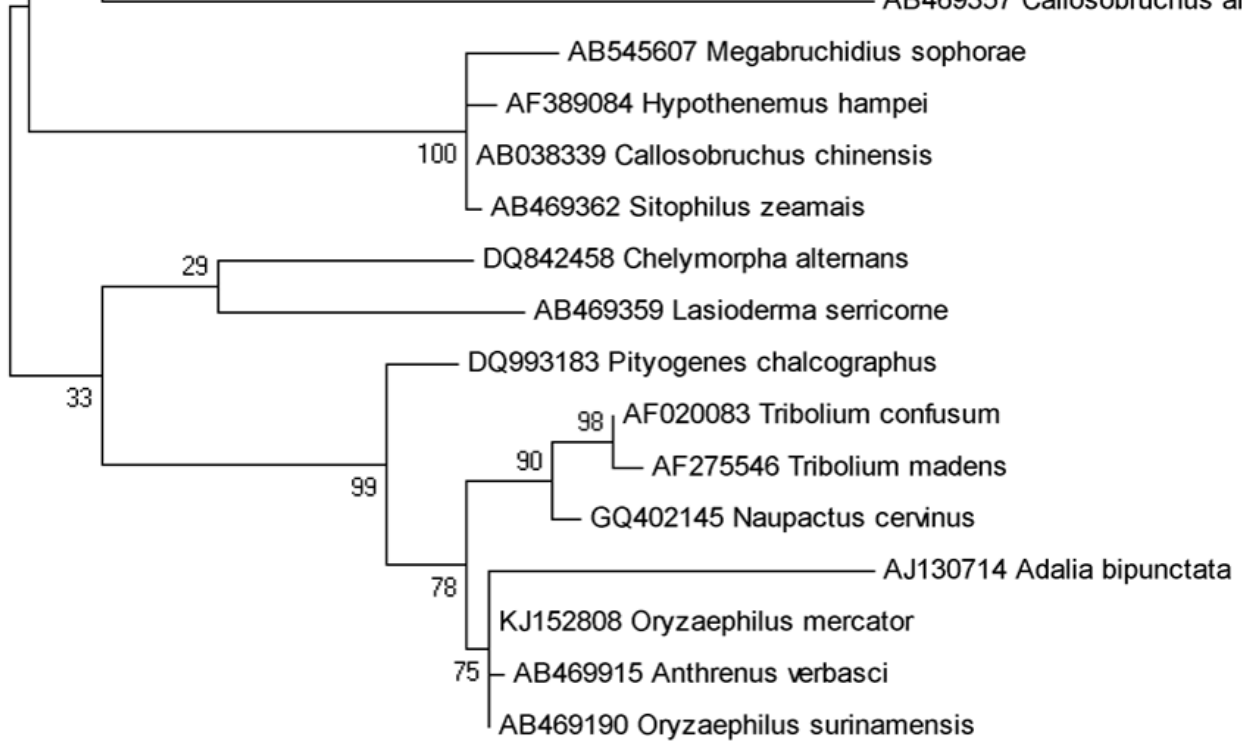

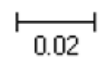

(B)

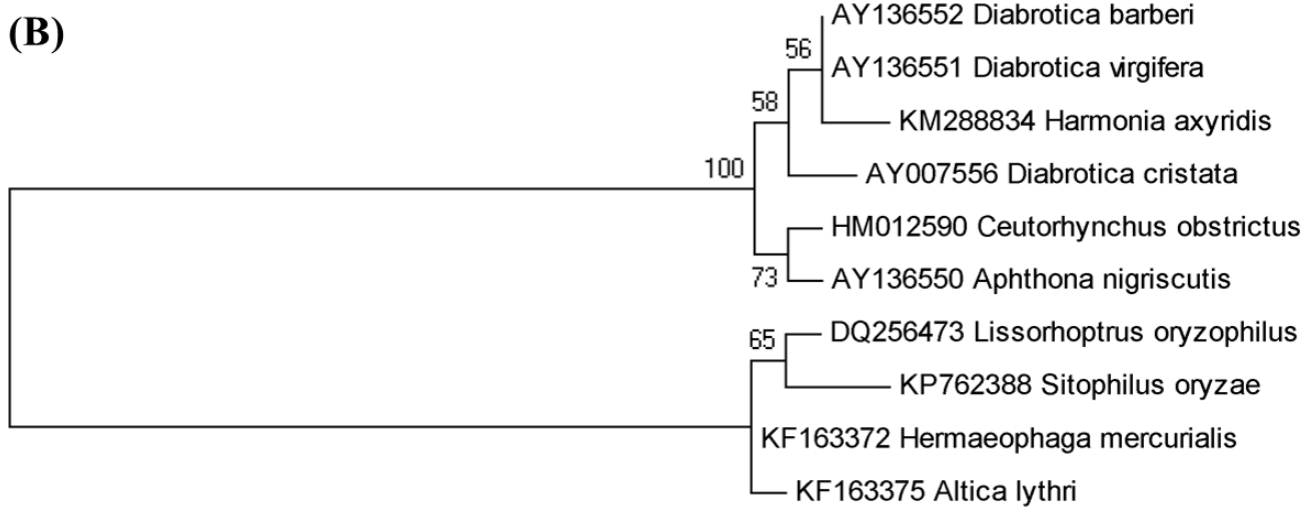

0.01

Figure 3. Maximum likelihood (ML) phylogenetic tree of previously reported Wolbachia positive individuals in coleopteran insects based on wsp (A) and ftsZ $(B)$ gene sequences. Bootstrap values shown next to nodes are based on 1000 replicates 


\section{Discussion}

Numerous invertebrates harbor endosymbiotic microorganisms, including terrestrial isopods (Rigaud et al., 2001), mites (Breeuwer and Jacobs, 1996), and all major orders of insects (Werren et al., 2000). Every insect species has its own set of endosymbiotic species that can vary greatly, even within the same insect species. The variation depends on factors such as sex, life stage, biotype, and geographic location (Pan et al., 2012). Wolbachia is one of the widespread ubiquitous intracellular bacterial symbionts that have evolved several phenotypic strategies (male killing, parthenogenesis, feminization and cytoplasmic incompatibility) to manipulate the reproductive system of the various insect, nematodes, crustacean etc.

In various weevils, these endosymbionts are broadly investigated and reported to have extremely interdependent associations like in Nardonella and many members of Dryophthoridae. For example, West Indian sweet potato weevil, Euscepes postfasciatus (Fairmaire), when endosymbionts were removed through the utilization of antibiotics, its structure, size, body weight, and developmental rate was significantly reduced (Kuriwada et al., 2010). Wolbachia were reported from $\approx 30$ weevils (Lachowska et al., 2010) so far which is quite a large number as its abundance. However, as a whole, current knowledge of the bacterial communities and their associations with natural hosts are still limited. In the context of Wolbachia importance as a bio-control agent and broad existence in all arthropods especially in Coleopteran insects, we planned a study to unravel the question about the presence of Wolbachia sp. in RPW. Furthermore, to improve our previous knowledge about the existence of Wolbachia in weevils, we compiled up to date known Wolbachia-inherited weevils in this study. Based on our results, we confirmed that Wolbachia is not present in both laboratory reared and field collected specimens of RPW in any developmental stage. A PCR assay based study was conducted by Bordenstein et al. (2003) in a diverse set of nonfilariid species and the results dmonstrated the absent of Wolbachia in Nonfilariid Nematodes which is quite similar to our study conclusion. Other studies such as Voronin et al. (2015), McNulty et al. (2012) are also in line with our results. There could be several possible reasons such as co-evolution, stochasticity (Jansen et al., 2008), fitness costs incurred by infection (Sarakatsanou et al., 2011; Suh et al., 2013; Dykstra et al., 2014), high temperature, (Clancy et al., 1998), imperfect maternal transmission and/or agricultural application of bactericide (McManus et al., 2002), high host specificity all are behind the absence of Wolbachia in RPW but without any authentic surveys all explanation remains possibilities which still need to be determined.

The congruence of Wolbachia sp. with filariid dated back to about 100 million years suggesting that Wolbachia sp. has coevolved with the host organism and became an integral organ of the host (Casiraghi et al., 2001). Lo et al. (2002) has suggested that Wolbachia sp. are highly host specific. However, recent studies have shown that this can be cultured in vitro as well as can be injected and manipulated in other non-host organisms which not only infects host soma but also infects somatic tissue and maintain this infection into various generation (stock populations of Drosophila melanogaster) after initial injections of Wolbachia sp. Transfection of Wolbachia sp. from naturally infected host to non-host organism such as RPW would open new avenues for developing an effective bio-control strategy against this devastating pest of palm trees. 


\section{Conclusion and future prospects}

Wolbachia species are widely distributed in arthropods, mites, terrestrial isopods and all major insect orders particularly in Coleopteran insects. However, in this study, there is no evidence of Wolbachia presence in all tested developmental stages either laboratory reared or field collected specimens of RPW at any geographical locations of China. Therefore, on the basis of our results we concluded that Wolbachia sp. is not present in the population of RPW. Greater awareness, in combination with rapidly expanding knowledge base of Wolbachia (particularly in the areas of genomics, cell biology and molecular biology) and comparable endosymbionts, offers new directions for incorporating them in bio-control programs. The capacity of Wolbachia that cause $\mathrm{Cl}$ in arthropod species has created interest in their use as a mechanism to drive desirable traits (for example resistance to disease) into insect vector populations. The use of Wolbachia infected males is also being developed as a mechanism to decrease pest populations by inducing elevated $\mathrm{Cl}$, similar to the use of sterile male programs to control pest insects. However, incorporation of Wolbachia in biocontrol research strategies may be restricted by technical challenges. For example, infections can be manipulated by elimination, transfection or genetic modification. The former has been achieved in many cases, transfection has been accounted less frequently, and genetic modification has yet to be achieved. However, given advances in recent years, we are optimistic that results of ongoing and future research will expand opportunities to use Wolbachia and similar endosymbiotic bacteria in bio-control programs.

Acknowledgements. We are very grateful to the grant from the National Key R \& D Program of China (2017YFC1200605) and Fujian Science and Technology Special Project (2017NZ0003-1-6).

Conflict of interest. The authors declare to have no potential conflicts of interests.

\section{REFERENCES}

[1] Ali, H., Hou, Y., Tang, B., Shi, Z., Huang, B., Muhammad, A., Sanda, N. B. (2016): A way of reproductive manipulation and biology of Wolbachia pipientis. - Journal of Experimental Biology and Agricultural Sciences 4: 156-168.

[2] Ali, H., Muhammad, A., Hou, Y. (2018): Infection density dynamics and phylogeny of Wolbachia associated with coconut hispine beetle, Brontispa longissima (Gestro) (Coleoptera: Chrysomelidae) by multilocus sequence type (MLST) genotyping. - Journal of Microbiology and Biotechnology (In press).

[3] Avtzis, D. N., Arthofer, W., Stauffer, C. (2008): Sympatric occurrence of diverged mtDNA lineages of Pityogenes chalcographus (Coleoptera, Scolytinae) in Europe. Biological Journal of the Linnean Society 94: 331-340.

[4] Baldo, L., Hotopp, J. C. D., Jolley, K. A., Bordenstein, S. R., Biber, S. A., Choudhury, R. R., Hayashi, C., Maiden, M. C., Tettelin, H., Werren, J. H. (2006): Multilocus sequence typing system for the endosymbiont Wolbachia pipientis. - Applied and Environmental Microbiology 72: 7098-7110.

[5] Blagrove, M. S., Arias-Goeta, C., Failloux, A. B., Sinkins, S. P. (2012): Wolbachia strain wMel induces cytoplasmic incompatibility and blocks dengue transmission in Aedes albopictus. - Proceedings of the National Academy of Sciences 109: 255-260.

[6] Bordenstein, S. R. (2003): Symbiosis and the origin of species. - Insect Symbiosis 1: 347.

[7] Bordenstein, S. R., Fitch, D. H., Werren, J. H. (2003): Absence of Wolbachia in nonfilariid nematodes. - Journal of Nematology 35: 266. 
[8] Breeuwer, J., Jacobs, G. (1996): Wolbachia: intracellular manipulators of mite reproduction. - Experimental and Applied Acarology 20: 421-434.

[9] Campbell, B. C., Bragg, T. S., Turner, C. E. (1992): Phylogeny of symbiotic bacteria of four weevil species (Coleoptera: Curculionidae) based on analysis of $16 \mathrm{~S}$ ribosomal DNA. - Insect Biochemistry and Molecular Biology 22: 415-421.

[10] Casiraghi, M., Favia, G., Cancrini, G., Bartoloni, A., Bandi, C. (2001): Molecular identification of Wolbachia from the filarial nematode Mansonella ozzardi. Parasitology Research 87: 417-420.

[11] Chen, S. J., Lu, F., Cheng, J. A., Jiang, M. X., Way, M. O. (2012): Identification and biological role of the endosymbionts Wolbachia in rice water weevil (Coleoptera: Curculionidae). - Environmental Entomology 41: 469-477.

[12] Clancy, D. J., Hoffmann, A. A. (1998): Environmental effects on cytoplasmic incompatibility and bacterial load in Wolbachia-infected Drosophila simulans. Entomologia Experimentalis et Applicata 86: 13-24.

[13] Clark, T. L., Meinke, L. J., Skoda, S. R., Foster, J. E. (2001): Occurrence of Wolbachia in selected diabroticite (Coleoptera: Chrysomelidae) beetles. - Annual Entomological Society of America 94: 877-885.

[14] Dedeine, F., Bouletreau, M., Vavre, F. (2005): Wolbachia requirement for oogenesis: occurrence within the genus Asobara (Hymenoptera, Braconidae) and evidence for intraspecific variation in A. tabida. - Heredity 95: 394-400.

[15] Dykstra, H. R., Weldon, S. R., Martinez, A. J., White, J. A., Hopper, K. R., Heimpel, G. E., Asplen, M. K., Oliver, K. M. (2014): Factors limiting the spread of the protective symbiont Hamiltonella defensa in Aphis craccivora aphids. - Applied and Environmental Microbiology 80: 5818-5827.

[16] Fenn, K., Blaxter, M. (2004): Are filarial nematode Wolbachia obligate mutualist symbionts?. - Trends in Ecology and Evolution 19: 163-166.

[17] Fenn, K., Conlon, C., Jones, M., Quail, M. A., Holroyd, N. E., Parkhill, J., Blaxter, M. (2006): Phylogenetic relationships of the Wolbachia of nematodes and arthropods. PLoS Pathogens 2: e94.

[18] Fialho, R. F., Stevens, L. (2000): Male-killing Wolbachia in a flour beetle. - Proceedings of the Royal Society of London. Series B 267: 1469-1473.

[19] Floate, K. D., Coghlin, P. C., Dosdall, L. (2011): A test using Wolbachia bacteria to identify Eurasian source populations of cabbage seedpod weevil, Ceutorhynchus obstrictus (Marsham), in North America. - Environmental Entomology 40: 818-823.

[20] Gazla, I., Carracedo, M. (2009): Effect of intracellular Wolbachia on interspecific crosses between Drosophila melanogaster and Drosophila simulans. - Genetics and Moleculer Research 8: 861-869.

[21] Giordano, R., Jackson, J. J., Robertson, H. M. (1997): The role of Wolbachia bacteria in reproductive incompatibilities and hybrid zones of Diabrotica beetles and Gryllus crickets. - Proceedings of the National Academy of Sciences 94: 11439-11444.

[22] Goryacheva, I., Blekhman, A., Andrianov, B., Gorelova, T., Zakharov, I. (2015): Genotypic diversity of Wolbachia pipientis in native and invasive Harmonia axyridis Pall., 1773 (Coleoptera, Coccinellidae) populations. - Russian Journal of Genetics 51: 731-736.

[23] Hilgenboecker, K., Hammerstein, P., Schlattmann, P., Telschow, A., Werren, J. H. (2008): How many species are infected with Wolbachia? A statistical analysis of current data. - FEMS Microbiology Letters 281: 215-220.

[24] Hosokawa, T., Koga, R., Kikuchi, Y., Meng, X. Y., Fukatsu, T. (2010): Wolbachia as a bacteriocyte-associated nutritional mutualist. - Proceedings of the National Academy of Sciences 107: 769-774.

[25] Howard, F. W., Giblin-Davis, R., Moore, D., Abad, R. G. (2001): Insects on Palms. CABI, Wallingford, UK. 
[26] Hurst, G. D., Jiggins, F. M., von der Schulenburg, J. H. G., Bertrand, D., West, S. A., Goriacheva, I. I., Zakharov, I. A., Werren, J. H., Stouthamer, R., Majerus, M. E. (1999): Male-killing Wolbachia in two species of insect. - Proceedings of the Royal Society of London. Series B 266: 735-740.

[27] Iwase, S., Tani, S., Saeki, Y., Tuda, M., Haran, J., Skuhrovec, J., Takagi, M. (2015): Dynamics of infection with Wolbachia in Hypera postica (Coleoptera: Curculionidae) during invasion and establishment. - Biological Invasions 17: 3639-3648.

[28] Jackel, R., Mora, D., Dobler, S. (2013): Evidence for selective sweeps by Wolbachia infections: phylogeny of Altica leaf beetles and their reproductive parasites. - Molecular Ecology 22: 4241-55.

[29] Jansen, V. A. A., Turelli, M., Godfray, H. C. J. (2008): Stochastic spread of Wolbachia. Proceedings of the Royal Society of London. Series B 275: 2769-2776.

[30] Jeong, G., Kang, T., Park, H., Choi, J., Hwang, S., Kim, W., Choi, Y., Lee, K., Park, I., Sim, H. (2009): Wolbachia infection in the Korean endemic firefly, Luciola unmunsana (Coleoptera: Lampyridae). - Journal of Asia-Pacific Entomology 12: 33-36.

[31] Jiggins, F. M., Hurst, G. D., Schulenburg, J. H. G., Majerus, M. E. (2001): Two malekilling Wolbachia strains coexist within a population of the butterfly Acraea encedon.Heredity 86: 161-166.

[32] Kaakeh, W., Khamis, A., Aboul-Nour, M. M. (2001): The Red Palm Weevil: the Most Dangerous Agricultural Pest, pp. 90-165. - United Arab Emirates University Press, Dubai.

[33] Kageyama, D., Narita, S., Imamura, T., Miyanoshita, A. (2010): Detection and identification of Wolbachia endosymbionts from laboratory stocks of stored-product insect pests and their parasitoids. - Journal of Stored Products Research 46: 13-19.

[34] Kambris, Z., Cook, P. E., Phuc, H. K., Sinkins, S. P. (2009): Immune activation by lifeshortening Wolbachia and reduced filarial competence in mosquitoes. - Science 326: 134-136.

[35] Kawasaki, Y., Ito, M., Miura, K., Kajimura, H. (2010): Superinfection of five Wolbachia in the alnus ambrosia beetle, Xylosandrus germanus (Blandford) (Coleoptera: Curuculionidae). - Bulletin of Entomological Research 100: 231-239.

[36] Kondo, N. I., Tuda, M., Toquenaga, Y., Lan, Y. C., Buranapanichpan, S., Horng, S. B., Shimada, M., Fukatsu, T. (2011): Wolbachia infections in world populations of bean beetles (Coleoptera: Chrysomelidae: Bruchinae) infesting cultivated and wild legumes. Zoological Science 28: 501-508.

[37] Kuriwada, T., Hosokawa, T., Kumano, N., Shiromoto, K., Haraguchi, D., Fukatsu, T. (2010): Biological role of Nardonella endosymbiont in its weevil host. - PloS One 5: e13101.

[38] Lachowska, D., Kajtoch, L., Knutelski, S. (2010): Occurrence of Wolbachia in central European weevils: correlations with host systematics, ecology, and biology. Entomologia Experimentalis et Applicata 135: 105-118.

[39] Li, Y., Zeng-Rong, Z., Ruiting, J., Lian-Sheng, W. (2009): The red palm weevil, Rhynchophorus ferrugineus (Coleoptera: Curculionidae), newly reported from Zhejiang, China and update of geographical distribution. - Florida Entomologist 92: 386-387.

[40] Li, Y. Y., Fields, P., Pang, B. P., Coghlin, P., Floate, K. (2015): Prevalence and diversity of Wolbachia bacteria infecting insect pests of stored products. - Journal of Stored Products Research 62: 93-100.

[41] Lo, N., Casiraghi, M., Salati, E., Bazzocchi, C., Bandi, C. (2002): How many Wolbachia supergroups exist? - Molecular Biology and Evolution 19: 341-346.

[42] Malloch, G., Fenton, B. (2005): Super-infections of Wolbachia in byturid beetles and evidence for genetic transfer between A and B super-groups of Wolbachia. - Molecular Ecology 2: 627-637. 
[43] Malumphy, C., Moran, H. (2009): Red palm weevil, Rhynchophorus ferrugineus. Plant pest factsheet. - $\quad$ www.fera.defra.gov.uk/plants/publications/ documents/factsheets/redPalmWeevil.pdf (accessed 7 June 2011).

[44] McManus, P. S., Stockwell, V. O., Sundin, G. W., Jones, A. L. (2002): Antibiotic use in plant agriculture. - Annual Review Phytopathology 40: 443-465.

[45] McNulty, S. N., Fischer, K., Mehus, J. O., Vaughan, J. A., Tkach, V. V., Weil, G. J., Fischer, P. U. (2012): Absence of Wolbachia endobacteria in Chandlerella quiscali, an avian filarial parasite. - Journal of Parasitology: 98(2): 382-387.

[46] Miller, W. J., Ehrman, L., Schneider, D. (2010): Infectious speciation revisited: impact of symbiont-depletion on female fitness and mating behavior of Drosophila paulistorum. PLoS Pathogens. - 6: e1001214.

[47] Ming, Q. L., Shen, J. F., Cheng, C., Liu, C. M., Feng, Z. J. (2015): Wolbachia infection dynamics in Tribolium confusum (Coleoptera: Tenebrionidae) and their effects on host mating behavior and reproduction. - Journal of Economic Entomology 108: 1408-1415.

[48] Montagna, M., Chouaia, B., Sacchi, L., Porretta, D., Martin, E., Giorgi, A., Lozzia, G. C., Epis, S. (2014): A new strain of Wolbachia in an Alpine population of the viviparous Oreina cacaliae (Coleoptera: Chrysomelidae). - Environmental Entomology 43: 913922.

[49] Murphy, S., Briscoe, B. (1999): The red palm weevil as an alien invasive: biology and the prospects for biological control as a component of IPM. - Biocontrol News and Information 20: 35-46.

[50] Negri, I., Pellecchia, M., Mazzoglio, P., Patetta, A., Alma, A. (2006): Feminizing Wolbachia in Zyginidia pullula (Insecta, Hemiptera), a leafhopper with an XX/X0 sexdetermination system. - Proceedings of the Royal Society of London. Series B 273: 2409-2416.

[51] Oberprieler, R. G., Marvaldi, A. E., Anderson, R. S. (2007): Weevils, weevils, weevils everywhere. - Zootaxa 1668: 491-520.

[52] Osborne, S. E., Iturbe-Ormaetxe, I., Brownlie, J. C., O’Neill, S. L., Johnson, K. N. (2012): Antiviral protection and the importance of Wolbachia density and tissue tropism in Drosophila simulans. - Applied and Environmental Microbiology 78: 6922-6929.

[53] Pan, H., Li, X., Ge, D., Wang, S., Wu, Q., Xie, W., Jiao, X., Chu, D., Liu, B., Xu, B. (2012): Factors affecting population dynamics of maternally transmitted endosymbionts in Bemisia tabaci. - PloS One 7: e30760.

[54] Poinsot, D., Charlat, S., Mercot, H. (2003): On the mechanism of Wolbachia-induced cytoplasmic incompatibility: Confronting the models with the facts. - Bioessays 25: 259265.

[55] Hou, Y., Weng, Z. (2010): Temperature-dependent development and life table parameters of Octodonta nipae (Coleoptera: Chrysomelidae). - Environmental Entomology 39: 1676-1684.

[56] Pu, Y. C., Hou, Y. M. (2016): Isolation and identification of bacterial strains with insecticidal activities from Rhynchophorus ferrugineus Oliver (Coleoptera: Curculionidae). - Journal of Applied Entomology 140: 617-626.

[57] Rigaud, T. (1997): Inherited Microorganisms and Sex Determination of Arthropod Hosts. - In: O’Neill, S. L., Hoffmann, A. A., Werren, J. H. (eds.) Influential Passengers: Inherited Microorganisms and Arthropod Reproduction, pp. 81-102. - Oxford University Press, Oxford.

[58] Rigaud, T., Pennings, P., Juchault, P. (2001): Wolbachia bacteria effects after experimental interspecific transfers in terrestrial isopods. - Journal of Invertebrate Pathology 77: 251-257.

[59] Rodriguero, M., Confalonieri, V., Guedes, J., Lanteri, A. (2010): Wolbachia infection in the tribe Naupactini (Coleoptera, Curculionidae): association between thelytokous parthenogenesis and infection status. - Insect Moleclar Biology 19: 631-640. 
[60] Roehrdanz, R., Levine, E. (2007): Wolbachia bacterial infections linked to mitochondrial DNA reproductive isolation among populations of northern corn rootworm (Coleoptera: Chrysomelidae). - Annual Entomological Society of America 100: 522-531.

[61] Roehrdanz, R., Olson, D., Bourchier, R., Sears, S., Cortilet, A., Fauske, G. (2006): Mitochondrial DNA diversity and Wolbachia infection in the flea beetle Aphthona nigriscutis (Coleoptera: Chrysomelidae): an introduced biocontrol agent for leafy spurge. - Biological Control 37: 1-8.

[62] Sarakatsanou, A., Diamantidis, A. D., Papanastasiou, S. A., Bourtzis, K., Papadopoulos, N. T. (2011): Effects of Wolbachia on fitness of the Mediterranean fruit fly (Diptera: Tephritidae). - Journal of Applied Entomology 135: 554-563.

[63] Son, Y., Luckhart, S., Zhang, X., Lieber, M. J., Lewis, E. E. (2008): Effects and implications of antibiotic treatment on Wolbachia-infected vine weevil (Coleoptera: Curculionidae). - Agricultural and Forest Entomology 10: 147-155.

[64] Stouthamer, R., Breeuwer, J. A., Hurst, G. D. (1999): Wolbachia pipientis: microbial manipulator of arthropod reproduction. - Annual Reviews in Microbiology 53: 71-102.

[65] Suh, E., Dobson, S. L. (2013): Reduced competitiveness of Wolbachia infected Aedes aegypti larvae in intra- and interspecific immature interactions. - Journal of Invertebrate Pathology 114: 173-177.

[66] Tagami, Y., Miura, K. (2004): Distribution and prevalence of Wolbachia in Japanese populations of Lepidoptera. - Insect Molecular Biology 13: 359-364.

[67] Tamura, K., Peterson, D., Peterson, N., Stecher, G., Nei, M., Kumar, S. (2011): MEGA5: molecular evolutionary genetics analysis using maximum likelihood, evolutionary distance, and maximum parsimony methods. - Molecular Biology and Evolution 28: 2731-2739.

[68] Vega, F. E., Benavides, P., Stuart, J. A., O’Neill, S. L. (2002): Wolbachia infection in the coffee berry borer (Coleoptera: Scolytidae). - Annual Entomological Society of America 95: 374-378.

[69] Voronin, D., Abeykoon, A. M., Gunawardene, Y. S., Dassanayake, R. S. (2015): Absence of Wolbachia endobacteria in Sri Lankan isolates of the nematode parasite of animals Setaria digitata. - Veterinary Parasitology 207(3-4): 350-354.

[70] Werren, J. H., Windsor, D. M. (2000): Wolbachia infection frequencies in insects: evidence of a global equilibrium?. - Proceedings of the Royal Society of London. Series B 267: 1277-1285.

[71] Zhang, X., Luckhart, S., Tu, Z., Pfeiffer, D. G. (2010): Analysis of Wolbachia strains associated with Conotrachelus nenuphar (Coleoptera: Curculionidae) in the eastern United States. - Environmental Microbiology 39: 396-405.

[72] Zhou, W., Rousset, F., O’Neill, S. (1998): Phylogeny and PCR-based classification of Wolbachia strains using wsp gene sequences. - Proceedings of the Royal Society of London. Series B 265: 509-515.

[73] Zug, R., Hammerstein, P. (2012): Still a host of hosts for Wolbachia: analysis of recent data suggests that $40 \%$ of terrestrial arthropod species are infected. - PloS one 7: e38544. 